\title{
SISTEMA, IRONÍA E HISTORIA: FRIEDRICH SCHLEGEL Y HEGEL EN DISPUTA
}

System, Irony and History Friedrich Schlegel and Hegel in Dispute

\author{
GONZALO PORTALES \\ Universidad Austral de Chile \\ gportale@uach.cl
}

Resumen

El artículo busca una comprensión de los trabajos académicos acerca de filosofía de la historia desarrollados por Hegel y Friedrich Schlegel a partir del análisis de lo que considera una disputa constante entre idealismo y romanticismo, en la que se encuentran involucradas tanto la idea de una exposición sistemática inherente a la filosofía en tanto ciencia, como así también el recurso retórico a la ironía y el enfrentamiento confesional de los cristianismos posteriores a la Reforma y su concepto de historia universal.

Palabras clave: Sistema; Ironía; historia; disputa filosófica.

Abstract:

The article aims to reach an understanding of the scholarly work developed by Hegel and Friedrich Schlegel concerning the Philosophy of History, from the analysis of what is considered as a constant dispute between idealism and romanticism, in which the ideas of a systematic exposition, inherent to philosophy as science, as well as the rhetorical resort to irony and the confessional confrontation of Christianities following the Reformation and its universal history.

Key words: System; Irony; history; philosophical dispute.

\section{INTRODUCCIÓN}

Que la historia de la filosofía bien puede ser interpretada como un campo de batalla en el que la polémica parece ser la que mueve la constitución original del pensamiento propio, es algo que se deja constatar con cierta facilidad, si se observa la constante pugna entre sistemas, escuelas y corrientes, así como ella se habría dado desde la Antigüedad clásica y sus epígonos helenistas hasta el presente configurado antes que nada por el apremiante abandono de una modernidad siempre inconclusa. El tópico de la confrontación entre ser y devenir, ejemplificado desde la filosofía anterior a Sócrates con los nombres de Parménides y Heráclito, la dialéctica rupturista de la relación maestro discípulo, la confrontación entre sectas competitivas durante el mundo grecorromano, la agresiva Disputatio protagonizada por la rivalidad de órdenes religiosas en el seno de las primeras universidades, así como el talante refundacional característico del pensamiento moderno, especialmente de la tradición cartesiana, ofrecen una imagen destacada del modo 


\section{Gonzalo Portales}

eminentemente polémico que habría caracterizado al transcurso de la filosofía a lo largo de toda su historia ${ }^{1}$.

El siglo XIX, principalmente en los territorios de lengua alemana, parece haber extendido este estado de cosas hasta un verdadero bellum omnia contra omnes, en la medida en que la relativa unidad de intereses que se manifestaba en el esfuerzo filosófico postkantiano -reunido, tal vez, de manera cómplice y solidaria, ante la gigantesca tarea que demandaba la superación del criticismo-, terminó, sin embargo, disolviéndose con gran rapidez en una diversidad filosófica que arrasó a su paso con antiguas amistades juveniles y con proyectos compartidos de subversión epocal, tanto en el ámbito de lo político como así también en la renovación teórica de la ciencia y del arte. Este es el tiempo en que se produce el nacimiento de aquello que la historiografía filosófica formal ha denominado de manera reiterada Idealismo y Romanticismo, interpretando a su vez a ambos movimientos como si en ellos se tratará de intentos guiados sobre todo por la búsqueda del absoluto y por la recuperación de una unidad de mundo que el criticismo había puesto a prueba de forma radical, concluyendo en lo que estos autores percibían como restos ininteligibles que quedaban en un afuera de la comprensibilidad y por tanto también externos al objeto propio de la filosofía. Pero, los caminos derivados de esta vasta tarea con objetivo común se mostrarán, ya en un futuro inmediato, no solo divergentes, sino en ocasiones también francamente contradictorios.

\section{SISTEMA}

En la actualidad se ha acentuado frecuentemente, -por motivos que aluden, según mi opinión, a problemas o apremios que ocasiona el cambio de época y su ajuste de cuentas teórico-conceptual con el pasado decimonónico- aquella particular confrontación que se advierte en las diferentes reacciones frente a la exigencia planteada en aquel momento de que la filosofía debía expresarse con necesidad como sistema. Desde el Idealismo este requerimiento se manifiesta en el temprano anuncio del advenimiento de un tiempo inminente en que se demandará el abandono del nombre tradicional (Philosophia), para reemplazarlo directamente por el concepto de ciencia, como lo expresa el proyecto y la empresa de una Wissenschaftslehre propuestos por Fichte a partir de $1794^{2}$, una ciencia,

\footnotetext{
${ }^{1}$ Aun cuando este tópico es combatido desde la filosofía en cada generación -piénsese por ejmplo, para el mundo contemporáneo, en los esfuerzos de Heidegger por desarmar el lugar común de la contradictio Parménides-Heráclito-, es evidente que la tradición escolar siempre se vuelve a apoyar en este punto de vista que simplifica la mirada histórica y la enseñanza formal de la disciplina.

${ }^{2}$ Me refiero a la primera de las exposiciones de la Wissenschaftslehre, publicada en 1794 con el título Ueber den Begriff der Wissenschaftslehre. Ver Portales (2014, p. 6): "Fichte proclama [allí] el acontecimiento de un cambio que constituye una verdadera fisura epocal -técnicamente dicho, una catástrofe-, una transformación en la que se debe abandonar el término filosofía y su acepción puramente volitiva en relación al saber o sabiduría y reemplazarlo por un concepto que pueda 126 | AlPHA No50 (Julio 2020) PÁGS. 125-143. ISSN 07 16-4254
} 
empero, se advierte con insistencia, que deberá tomar inevitablemente la forma de un sistema. De manera más explícita aún, asevera el joven Hegel en los inicios de su así llamado período de Jena, cuando sostiene -en referencia a Fichte, a Schelling y a él mismo- que lo que distingue en sus fundamentos a la filosofía de su tiempo de toda la anterior es que ella se enfrenta irremediablemente a la necesidad (Bedürfnis) de "producir una totalidad del saber, un sistema de la ciencia"3. En abierta alusión a Kant y a su abrumador legado, el mismo texto afirma con cierta irreverencia que "el filosofar que no se construye como sistema, es [o se manifiesta como] una huida constante ante las limitaciones"4. Frente a esta imagen de paralización teórica, me parece plausible pensar que el carácter revolucionario del movimiento reflexivo del yo fichteano, protagonista de la Wissenschaftslehre, haya sido percibido por la primera recepción - ante todo- en el hecho de que en él se expresa y desarrolla la capacidad de arrasar, precisamente, con estas tenaces limitaciones (Beschränkungen), en la medida en que en su camino de vuelta a sí desde la enajenación, incorpora a la subjetividad toda alteridad que intente aún algún tipo de resistencia objetual (no-yo), constituyéndose de este modo en el yo absoluto, en una totalidad autónoma, autoconsciente, autokinética y autopoiética.

Tal vez la expresión más diáfana de esta nueva idea de subjetividad sin residuos ni antagonismo, compartida por idealistas y románticos en la Jena de comienzos de siglo, sea la que se enuncia en un célebre pasaje, múltiples veces citado y discutido, del prólogo a la Fenomenología del Espíritu de Hegel, publicada en 1807. Allí se dice de manera concluyente: "Lo verdadero es el todo". Y se explica a continuación, adelantándose a la objeción que podría advertir una perspectiva puramente anacrónica en dicha afirmación: "Pero el todo es solo la esencia que se acaba y completa a través de su desarrollo. De lo absoluto ha de decirse que es, esencialmente, resultado, y que recién al final es lo que es en verdad; y en esto justamente consiste su naturaleza: en ser algo real efectivo (Wirkliches), ser sujeto, o en llegar a ser él mismo"s.

Cuando en la segunda mitad del siglo XX estas obras ya no sean objeto de una lectura, por así decirlo, inmanente, es decir, de una lectura que intente aún determinar el

designar al saber ya no ambicionado, sino obtenido. Para ello es preciso renunciar a la noción de sophía y recuperar a la vez la de episthéme con el fin de hablar directamente de ciencia para caracterizar a aquello que alguna vez comenzó su larga carrera escolar como he prote philosophia".

${ }^{3}$ Ver G.W.F. Hegel: Diferenz des Fichteschen und Schelligschen Systems der Philosophie. En G.W.F.Hegel (1984 t. 2, p. 46).

4"Das Philosophieren, das sich nicht zum System konstruiert, ist eine beständige Flucht vor den Beschränkungen".

${ }^{5}$ Ver Hegel Phänomenologie des Geistes. En Hegel (1984 t.3 p. 24): "Das Wahre ist das Ganze. Das Ganze aber ist nur das durch seine Entwicklung sich vollendende Wesen. Es ist von dem Absoluten zu sagen, daß es wesentlich Resultat, daß es erst am Ende das ist, was es in Wahrheit ist; und hierin eben besteht seine Natur, Wirkliches, Subjekt oder Sichselbstwerden zu sein". 
difícil contenido filosófico de las mismas a partir de los complejos contextos involucrados en su gestación, en su desarrollo y en su ascendiente posterior, entonces el énfasis hermenéutico de la nueva recepción se desplazará principalmente hacia la operación que busca subrayar el carácter de totalidad y sistema como el explícito ejercicio de exclusiones autoritarias de toda alteridad, produciéndose de este modo una cierta denuncia de la violencia del reduccionismo conceptual inherente a la así llamada filosofía del idealismo absoluto. Recriminación que, como se sabe, se expresará tanto a nivel teórico como también asociada a la Realpolitik y a sus dialécticas confrontacionales.

Tal vez el ejemplo más paradigmático de este modo de proceder se exprese en el, por lo demás, magnífico libro Totalidad e infinito de Emanuel Levinás, en el que ya el nombre propio del filósofo, el nombre Hegel, parece expresar un común acuerdo entre escritor y lector en el que se lo entiende como una denominación que contiene en sí misma el significado de toda su obra filosófica. Así, mientras en la controversia de este ensayo con el idealismo decimonónico se menciona - a lo largo de todo el libro y no en un acápite determinado- catorce veces directamente el nombre propio y en otras nueve ocasiones se alude a él en su forma adjetiva, ya sea calificando algo de hegeliano o señalando a sus epígonos, se cita, sin embargo, solo en una ocasión un pequeño pasaje de la Fenomenología del Espíritu en la traducción francesa de Jean Hyppolite, modificada e intervenida. El párrafo del texto del tercer capítulo de la sección Conciencia, que lleva por título Fuerza y Entendimiento, fenómeno y mundo suprasensible dice, según la versión de Levinás, lo siguiente: "Me distingo yo mismo de mí mismo y, en este proceso, es inmediatamente (evidente) para mí que lo que es distinto no es distinto. Yo, el Homónimo, me opongo a mí mismo, pero lo que ha sido distinguido y puesto como diferente es, en tanto que inmediatamente distinguido, desprovisto para mí de toda diferencia"6.

De la cabal tautología (o quizás habría que hablar más bien de tautonomía) ontológica manifestada en pasajes de esta índole, de los que se podrían mencionar

\footnotetext{
${ }^{6}$ Reproduzco aquí los textos involucrados para que el lector dirima acerca de la cuestión del modo de citar y sus libertades:

Hyppolite: "Je me distingue moi-même de moi-même, et, dans ce mouvement c'est imédiatement pour moi que ce terme distinct n'est pas distinct. Moi, l'Homonyme, je me repousse moi-même de moi-même, mais ce terme distinct, ce quelque chose posé comme inégal, immédiatement quand il est distinct, ne constitue plus pour moi aucune différence".

Levinás: "Je me distingue moi-même de moi-même et, dans ce processus, il est immédiatement (évident) pour moi que ce qui est distinct n'est pas distinct. Moi, l'Homonyme, j e me repousse moimême, mais ce qui a été distingué et pose comme différent est, en tant qu'immédiatement distingué, dépourvu pour moi de toute difference".

Hegel: "Ich unterscheide mich von mir selbst, und es ist darin unmittelbar für mich, daß dies Unterschiedene nicht unterschieden ist. Ich, das Gleichnamige, stoße mich von mir selbst ab; aber dies Unterschiedene, Ungleich-Gesetzte ist unmittelbar, indem es unterschieden ist, kein Unterschied für mich".
}

128 | AlPHa No50 (Julio 2020) PÁGS. 125-143. ISSN 07 16-4254 
ciertamente varios más en diversos contextos de la obra hegeliana, se podría desprender sin posibilidad de equivocidad alguna, aquello que Levinás señala con acierto como la imperiosa negación de la diferencia, una forma de la Aufhebung, para decirlo en lenguaje técnico, que se deja ver en tanto conditio sine qua non para la realización no solo de la plenitud idéntica a sí de la autoconciencia, sino también para el advenimiento final de ese telos que solo se cumple en la totalidad sistemática de la ciencia, en el saber absoluto.

Tengo la convicción de que ha sido precisamente en relación con esta cuestión de la reducción de la alteridad, que ha irrumpido con fuerza en las últimas décadas ciertas interpretaciones que distinguen en ella una de las más inquietantes disputas entre Romanticismo e Idealismo en su historia decimonónica. Estimulada, sin duda, por el excelente y monumental trabajo editorial de la edición crítica de las obras de Friedrich Schlegel, liderado por Ernst Behler desde mediados del siglo XX y que se encuentra aún en proceso, la discusión actual, en la que me incluyo ${ }^{7}$, ha persistido en recuperar de manera peculiar tanto el concepto teórico como así también la praxis escritural del fragmento en tanto dispositivo antisistemático y con ello restaurador de la diferencia, emancipándola de esa especie de presidio topológico o reclusión dialéctica que la confinaba al lugar de lo puramente conservado-negado, de lo Aufhehobenes, en el movimiento reflexivo de la autoconciencia así como este aparece en la fenomenología hegeliana.

La rehabilitación romántica de la expresión latina fragmentum, que en sus orígenes designa la ruina y con ello al puro vestigio incompleto de lo que ya no comparece, puede ser percibida con buenos argumentos como una directa confrontación con las anteriormente mencionadas aspiraciones de totalidad provenientes de los inicios del idealismo alemán. No solo de aquellas que apuntan a la estructura conceptual de la filosofía como sistema, como totalidad del saber, sino también a las que se refieren a la escritura misma de esos tratados de la culminación de la ciencia. Es decir, la fragmentariedad -reivindicada con tanto ímpetu por el romanticismo- indicaría también según esto la imposibilidad metodológica en un plano puramente literario o de producción textual, manifestando con evidencia la necesaria desintegración inherente a la escritura de la obra sistemática, mostrando la inevitable frustración del pensar frente a aquello que en la segunda mitad del mismo siglo se identificará como el fracaso de la gramática.

Comparto, sin embargo, con algunos distinguidos investigadores del romanticismo, la opinión de que lo involucrado en esta disputa adquirió muchísimo más relevancia en la discusión filosófica durante el siglo XX, que la que realmente pudo haber tenido en la rivalidad de su historia decimonónica, ya que se advierte que la señalada falta de proporción entre pensar y lenguaje no fue experimentada de manera dramática por el romanticismo temprano, sino que la resuelta oposición entre fragmento y totalidad parece haber sido más bien tolerada como una forma de oposición con derecho a subsistir en su antítesis, sin

\footnotetext{
${ }^{7}$ Ver Portales y Onetto (2005, p. 279 y ss.).
} 


\section{Gonzalo Portales}

necesidad de someterse a los efectos de la negación del proceso de superación, relacionándose más bien el uno con la otra y la otra con el uno mediante esa oscilación predialéctica conformada por la combinatoria infinita de la pura paradoja. Así lo formula Schlegel, justamente, en uno de los fragmentos que componen los 451 publicados por él en el primer número de la revista del Atheneo, dice el fragmento 53: "Es igualmente mortífero para el espíritu tener un sistema y no tener ninguno. Habrá que decidirse, por lo tanto, a unir ambas cosas"8.

Esta radical ambigüedad y sus consecuencias han sido señaladas del mismo modo con claridad por los autores del ensayo El absoluto literario cuando advierten, respecto de la interpretación contemporánea de esta cuestión disputada, que "nuestro tiempo emprende la tarea de verificar la 'actualidad del romanticismo'. Lo que se hace (siguiendo la última moda) a partir del motivo de un 'romanticismo' esencialmente rebelde al imperialismo de la Razón y del Estado, al totalitarismo del Cogito y del Sistema; de un romanticismo de revuelta libertaria y literaria [...]. Es cierto [agregan] que este motivo no es simplemente falso. Pero no está lejos de serlo si se descuida su reverso (o su anverso...), porque el Absoluto literario agrava y radicaliza el pensamiento de la totalidad y del Sujeto, infinitiza este pensamiento, y es por eso, precisamente, que mantiene el equívoco"9.

Por otra parte, creo conveniente tener en cuenta también -en relación precisa a este punto de la indeterminación frente a lo sistemático en filosofía y literatura- que el mismo autor de la hoy célebre fragmentaria filosófico-poética se propuso incluso en los años del cambio de siglo como tarea colectiva, junto con su hermano August Wilhelm y a su amigo Novalis, la formulación de una Enciclopedia, la que si bien no debía tener como objeto a las ciencias filosóficas, sino a las ciencias literarias, concuerda, no obstante, coincidiendo en ello con la intención primordial de la posterior obra de Hegel a partir de 1817, en adoptar la forma sistemática de la estructura que ordena a los saberes en sus ciclos progresivos, esto es a la elaboración de una taxonomía que junto con presentar los ciclos del saber desde la perspectiva de la parcialidad propia de la finitud y del laborioso esfuerzo de sus logros particulares, los ordena simultáneamente desde el punto de vista de una totalidad ya cumplida, que los precede ontológicamente y sin estas ellos solo se disgregarían en una completa dispersión carente de unidad y de forma ${ }^{10}$. Aunque la ejecución de esta Enciclopedia nunca se llevó a cabo, y pasó así a formar parte de los numerosos proyectos inconclusos del joven Schlegel, la mera propuesta de un trabajo de esta índole manifiesta, según creo, el ejercicio concreto de aquella libertad ecléctica que el fragmento recién citado otorgaba a la escritura romántica en referencia a los procedimientos sistemáticos,

\footnotetext{
${ }^{8}$ Friedrich Schlegel (1958 y ss., t. 2, p. 173).

${ }^{9}$ Lacoue-Labarthe / Nancy (1978, p. 26).

${ }^{10}$ Friedrich Schlegels Enzyklopädie der literarischen Wissenchaften im Unterschied zu Hegels Enzyklopädie der philosophischen Wissenchaften. En Behler (1988, p. 237).

130 | Alpha №50 (Julio 2020) PÁGS. 125-143. ISSN 07 16-4254
} 
evidenciando al mismo tiempo -y refutando con ello un extendido tópico- la existencia de una expresa continuidad en este movimiento filosófico-literario de reconocidas ambiciones de la Ilustración, incorporada en esta consentida herencia incluso su idea de progreso. ${ }^{11}$ Estas sucintas precisiones indican suficientemente, a mi juicio, que la interrogación en torno al sistema y a la restitución del valor del fragmento, si bien jugará un rol apreciable en la disputa entre Schlegel y Hegel, no parece haber poseído realmente, sin embargo, el lugar tan central que parte importante de la recepción de las obras de estos prestigiosos autores le ha otorgado durante el pasado siglo. La relatividad de su peso específico aumenta aún, cuando se advierte que la intencionalidad sistemática de los textos de Hegel se debe más a la intromisión filológico-editorial de sus discípulos y seguidores, sobre todo de la edición de sus "obras completas" por los así llamados amigos del difunto entre 1832 y 1845, que a su propia exposición escritural, la que en múltiples ocasiones se presenta de manera desordenada, inconclusa e incoherente, manifestando también titubeos que uno podría calificar de impropios para un pensamiento consecuentemente sistemático que procede desde la perspectiva omnisapiente de una totalidad ya cumplida.

\section{IRONÍA}

Se constata más bien que tanto la documentación publicada en vida como aquella que ha llegado a nosotros corregida y diferenciada gracias al notable trabajo de la edición crítica de las obras de Hegel, dirigida durante décadas por Otto Pöggeler, la que considera también los textos pertenecientes al legado o Nachla $\beta$, muestran sin reservas que una de las cuestiones primordiales de la polémica entre estos dos pensadores se funda antes que nada en la diversa percepción de la ironía y su derecho a formar parte del lenguaje estrictamente filosófico, así como había sido señalado en el siglo XIX por Kierkegaard en su tesis doctoral y por Dilthey en su admirable trabajo de reconstrucción de época en torno a la vida Schleiermacher ${ }^{12}$.

La tradición había sostenido una relación bastante estática con este concepto, manteniéndose su sentido prácticamente invariable desde la definición dada por Cicerón en la Antiguiedad, la recogida luego a fines del primer siglo de nuestra era por Quintiliano en su descripción de tropos y figuras retóricas en el libro IX de su Institutio Oratoria, hasta su descripción en el artículo correspondiente a su significado en la obra más representativa de la modernidad ilustrada: en la L'Encyclopédie o Dictionnaire raisonné des sciences, des arts et des métiers, publicada entre 1751 y 1772 por Diderot y d'Alambert.

\footnotetext{
11 En relación con la recepción de Condorcet en la obra de Schlegel, cf. Behler (1989, p. 103 y ss).

${ }^{12}$ El minucioso trabajo de Otto Pöggeler referente a la crítica hegeliana al romanticismo (1999, especialmente p. 121 y ss.), como así también el ensayo de Ernst Behler: Hegels Polemiken gegen die Ironie, En: Behler (1997, p. 115).
} 
Con esta pasividad filológica, reducida al sentido retórico de la ironía como aquella figura en la que se produce una comprensión contraria de aquello que se ha dicho, romperá, pues, en parte, Schlegel cuando integre operativamente a su obra una reflexión ad hoc acerca de esta noción y sus posibles significados. La que buscaba, en primer lugar -adecuado es recordarlo aquí- resolver una cuestión suscitada por la literatura. Esta motivación histórico-disciplinaria, explica que Schlegel recurra inicialmente a un peculiar matiz semántico de la ironía con el fin de dilucidar un problema estructural presente en algunas obras literarias producidas por el Romanticismo en su época preliminar. Particularmente por las novelas y cuentos de Ludwig Tieck y Clemens Brentano, los que fueron recibidos con cierta extrañeza por el lector burgués acostumbrado a un orden lineal y totalmente libre de sobresaltos en los acontecimientos narrados. Me refiero al así llamado Wendepunkt o punto de cambio (giro radical) en el que una evidente arbitrariedad o una expresa intromisión en el desenvolvimiento del relato literario rompe de improviso con el aura ficcional, exponiendo a dicho relato precisamente como mera ficción y develándolo por tanto como un producto sujeto a una voluntad exterior a él mismo, voluntad o autoría que normalmente suele mantenerse oculta en literatura para permitir de ese modo una armonía estética que garantice la unidad dramática, sin ella la narración, en este caso, perdería su soporte poético y pasaría a ser objeto de un juicio construido mediante razonamientos pertenecientes a una realidad completamente externa y con frecuencia además hostil a la literaria. La ironía aludida en este contexto, se manifiesta, pues, como un fuera de obra que al evocar inoportunamente el acto poiético que la precede, debilita a la vez el status entitativo del producto de la propia creación ficcional, situándolo en un escenario tal que incita a adoptar una perspectiva que lo expone al ridículo. En la ficción irónicamente interrumpida, podría concluirse, la obra de arte literaria revela su parentesco con la mentira, con el artificio o la mera simulación, como había advertido desde el comienzo Cicerón en su ensayo referido a las prácticas de la oratoria.

Si el recurso a la ironía y su intimidante potencia destructiva se hubiesen mantenido en este plano de significado y su uso restringido se hubiese destinado de manera exclusiva a problemas estéticos privativos de la literatura romántica, entonces lo más probable es que no se habría generado ninguna reacción polémica. Pero la investigación de Schlegel no se limitó al análisis de esta acepción particular del término, sino que se expandió asimismo arriesgadamente hacia otros ámbitos más allá de la consideración estética y de la crítica literaria. Así, en el fragmento que lleva el número 42 de aquellos que se conocen como Fragmentos Críticos, y que fueron publicados en la revista berlinesa Lyceum der schönen Künste, se sostiene que el auténtico lugar o hábitat propio de la ironía es la filosofia ("Die Philosophie ist die eigentliche Heimat der Ironie)"13.

\footnotetext{
${ }^{13}$ Esta expresión se encuentra en el Fragmento 42 del Lyceum. Ver Friedrich Schlegel (1958 y ss., t. 2, p.152).

132 | AlPHA No50 (Julio 2020) PÁGS. 125-143. ISSN 07 16-4254
} 
Ernst Behler ha señalado en uno de sus eruditos ensayos que con este vínculo, cuyo contexto permite afirmar que se refiere a los diálogos platónicos y a su exposición de la célebre eironeîa socrática, Schlegel habría buscado relacionar con toda intención a la moderna poética romántica con la filosofía antigua, ejemplificando de este modo además su postura frente a la querelle des anciens et des modernes, mostrando la frágil sustentabilidad de estos términos opuestos y su ostensible relatividad para una mirada sincrónica, cuando en el primer cuaderno de los Philosophische Lehrjare sostenga que "todo lo antiguo se renueva mediante el estudio de lo clásico y todo lo nuevo devendrá antiguo, es decir, clásico y antiguo, es decir, será superado, devendrá anticuado"14. Pero lo más significativo de esta analogía se encuentra, según mi opinión, en que la ironía socrática aquí aludida hace patente una modalidad de la figura retórica que tiene como efecto la imposibilidad de concluir que caracterizaría a toda discusión filosófica, la que siempre termina en una falta de respuesta a la interrogación envuelta en su cometido inicial. Los románticos proyectaban sin más a todo tiempo venidero la situación de profundo cambio que se estaba experimentando en la filosofía de su época, expresando de este modo el convencimiento de que ya no se alcanzaría algo así como una propuesta filosófica cuyas verdades pudiesen ser perdurables, una philosophia perennis, sino que el proceso del pensar quedaba desde ya abierto al infinito como una tarea que en rigor se debía presentar siempre y en cada caso como un transcurso interminabilis. Esta falta de cierre o conclusión deja ver también la interposición de una perturbadora incertidumbre respecto de los conceptos mismos que se encuentran involucrados en la expresión escritural de la filosofía, pues la ironía parece poner en riesgo la seguridad significativa otorgada por el horismós o definitio, de cuya prescindencia completa se derivaría el riesgo de ser arrojado a la pura indeterminación, a la promiscuidad semántica de una polisemia generalizada que vuelve imposible la comunicación, la literatura y, por supuesto, también, la ciencia.

Este es el mayor de los peligros en torno a esta cuestión que parece advertir Hegel, para quien la teoría de la ironía de Schlegel implica no solo una liviandad insoportable en el plano teórico y un perjudicial menoscabo del rigor conceptual, sino también una irresponsabilidad moral que socaba los cimientos jurídicos de la convivencia social. Por ello no puede sino rebelarse frente a un autor que sostiene que la ironía filosófica debe tomar la forma de la paradoja para evitar la sofística ${ }^{15}$, oscilando entre entusiasmo y skepsis, afirmando a su vez con desenfado que puesto que la filosofía es infinita, y su división es arbitraria, se debe deducir "que el sistema más acabado solo puede ser una

\footnotetext{
${ }^{14}$ Friedrich Schlegel (1958 y ss., t 18, p. 26 y Behler (1997 p. 92).

${ }^{15}$ Se trata aquí de los Kritische Fragmente, fragmento 48. Cf. también Friedrich Schlegel (1958 y ss., t 18, p. 123: Toda filosofía no paradójica es sofística, Jede nicht paradoxe Philosophie ist sophistisch. 


\section{Gonzalo Portales}

aproximación"16. Complaciéndose a su vez, por último, en la enunciación que proclama -según la interpretación de Dilthey bajo la directa influencia del misticismo de Jacob Böhme- que "la ironía es la clara conciencia de la eterna agilidad, del caos pleno e infinito"17. Se deja advertir además que la disputa adquiere aquí, a diferencia de la polémica respecto de la sistematicidad de la ciencia, una proporción muy equilibrada, pues así como se confirma que Schlegel mantuvo una reflexión teórica acerca de la ironía en toda su obra (las últimas alusiones pueden fecharse en 1829, pocos días antes de su muerte), asimismo se advierte que la crítica de Hegel vuelve a tener nuevamente vigencia en textos que se reparten a lo largo de su vida, desde sus obras tempranas de Jena hasta las célebres lecciones y escritos berlineses.

Presento ahora brevemente, conforme con un criterio expositivo de este trabajo y no a uno cronológico de la cuestión misma, algunos de los hitos que me parecen más representativos de esta intensa polémica emprendida por Hegel, la que adquirió rasgos de un enfrentamiento personal que buscaba incluso desacreditar frente a un juicio público el modo de vida y los hábitos "artísticos" o costumbres bohemias de su adversario ${ }^{18}$. Es posible constatar, en primer término, que por causa de su teoría de la ironía, Schlegel habría merecido ser desterrado de la tradición que piensa y filosofa a partir de la nueva subjetividad propuesta por Fichte, la que -como se observó anteriormente-románticos e idealistas aún compartían en los tiempos comunes de la época de Jena. Según la versión de Gustav Hohto, que se supone redactó el texto de las Lecciones de Estética a partir de sus propios apuntes y teniendo a la vista los manuscritos del mismo Hegel - perdidos durante el siglo XIX ${ }^{19}$-, pero que sin embargo mezcló en su edición arbitrariamente escritos provenientes de distintos semestres en que se trató de la filosofía del arte tanto en Heidelberg como en Berlín, en el último parágrafo introductorio Hegel habría expresado frente a sus estudiantes una determinación histórico-filosófica de lo que a su juicio debía ser entendido como dos caminos derivados de la teoría de la subjetividad de Fichte. El primero de ellos estaría ejemplificado en la obra de Schelling, el que habría elevado el punto de vista fichteano hasta una filosofía de perspectiva absoluta, en la medida en que habría otorgado a dicha subjetividad un contenido sustancial; el otro camino, en cambio, el de la ironía de Friedrich Schlegel, habría dejado de lado el carácter especulativo de aquella filosofía, continuando de este modo el "Yo" fichteano mediante un concepto de sujeto que expresaría una "subjetividad sin sustancia" (substanzlose Subjektivät) y que se habría mostrado incapaz de

\footnotetext{
${ }^{16}$ F. Schlegel: Philosophische Vorlesungen 1. En: Friedrich Schlegel (1958 y ss., t. 18, p. 12, p. 4 y 10 "Aus den Sätzen: die Philosophie ist unendlich; und ihre Eintheilung ist willkürlich, geht hervor, daß das vollendeste System nur Approximazion seyn kann".

17 "Ironie ist klares Bewußtsein der ewigen Agilitat, des unendlich vollen Chaos". Friedrich Schlegel (1958 y ss., t. 11, p. 263. Cf. W. Dilthey (1870, p. 361).

${ }^{18}$ Ver Behler (1997, p. 115).

${ }^{19}$ Ver Endres (2017, p. 384 y ss.).

134 | AlPha No50 (Julio 2020) PÁGS. 125-143. ISSN 07 16-4254
} 
alcanzar el prestigio del pensamiento especulativo ${ }^{20}$, pues en su apropiación de esta tradición con el fin de formular su concepto de ironía se habría tratado -acota en otro sitiode una "aplicación no filosófica del punto de vista de la subjetividad de Fichte"21.

Pero no será en la teoría de esta nueva subjetividad, sino más bien en la praxis del sujeto moral en donde radicaría, según Hegel, el efecto más nocivo de la ironía romántica. La literatura especializada, Hyppolite por ejemplo, ha determinado que en un pasaje de la Fenomenología del Espíritu de 1807 ubicado al final del tercer acápite del capítulo acerca del espíritu cierto de sí mismo, titulado la certeza moral, el alma bella, el mal y su perdón, en el que Hegel habría buscado resumir etapas anteriores antes de pasar a la exposición del saber absoluto, se puede identificar claramente a diversos autores y pensadores del romanticismo y su entorno como los destinatarios reales de lo allí expresado solo conceptualmente: mientras la noción de "genialidad moral" se refiere a Jacobi y la de "absoluta certeza de sí mismo" describe a Fichte, se observa que el concepto de "alma bella" es aplicado a Novalis, el de "hipocresía" a Schleiermacher, el de "corazón duro" a Hölderlin y, por último, a Friedrich Schlegel correspondería el concepto de "el mal declarado" ${ }^{22}$. Lo que aquí se afirma aún de manera velada, será expuesto sin ningún circunloquio en el parágrafo 140 de la filosofía del derecho, la que a diferencia de otras lecciones universitarias, sí fue publicada por Hegel como manual para sus estudiantes ${ }^{23}$. Allí se sostiene, en el tercer acápite del capítulo acerca de la moralidad, titulado el bien y la certeza moral, que la ironía debe ser considerada como "la cima de la subjetividad que se concibe a sí misma como lo último, Spitze der sich als das Letzte erfassenden Subjektivität'. Y se agrega que para ella "No es la cosa lo excelente, sino que el excelente soy yo, y soy el amo sobre la ley y la cosa, el cual, de ese modo, como su antojo, solo juega, y en esta conciencia irónica, en la que dejo hundirse lo supremo, solo gozo de mí mismo. Esta figura no solo es la vanidad de todo contenido ético del derecho, del deber y de las leyes -el mal, y precisamente el mal universal totalmente en sí (in sich)-, sino que ella añade también la forma, la vanidad subjetiva, de saberse a sí misma como esta vanidad de todo contenido y en este saber saberse como lo absoluto".

El tono y la intención de pasajes como este ha provocado que ciertos intérpretes hayan llegado a sostener que ya no podría hablarse simplemente de una polémica filosófica respecto de la ironía, sino que habría que referirse más bien a una denuncia sociopolítica, a

\footnotetext{
${ }^{20}$ Hegel (1984 t. 13Vorlesungen über Ästhetik I,, p. 93) y Pöggeler (1999, p. 45 y ss.).

${ }^{21}$ Hegel (1984 t. 20, p. 415 y ss.).

${ }^{22}$ Hyppolite (1946 Genèse t. II, p. 475 y ss. Véase también Behler (1997, p.116), Allí se alude al trabajo Die Beisetzung der Romantiker in Hegels Phänomenologie (1924) de Emanuel Hirsch como el primer ensayo que habría distinguido esta correspondencia entre conceptos y personas. Aun cuando la estructura del libro contempla todavía el capítulo Religión para arribar al capítulo El saber Absoluto, se puede hablar, sin embargo, también de un tránsito desde el espíritu al saber absoluto.

${ }^{23}$ Las lecciones acerca de filosofía del derecho tuvieron varias ediciones durante la vida de Hegel.
} 


\section{Gonzalo Portales}

una certera acusación moral, la que había sido levantada, además, desde un punto de vista que ni siquiera consideraba el contenido específico de la teoría de la ironía propuesta por su supuesto adversario ${ }^{24}$. Quizás por esto mismo, se comprenda que a pesar de las fuertes críticas a la filosofía de Hegel y su significado para la historia del idealismo, desarrolladas por Schlegel, por ejemplo en extensos pasajes de los Fragmentos sobre poesía y literatura de $1823^{25}$, y sobre todo en una de las últimas de sus lecciones vienesas, la dedicada a Filosofía de la vida de $1827^{26}$, no se encuentre, sin embargo, en toda su extensa obra, algo así como una respuesta directa a este devastador parágrafo de la Filosofía del derecho de Hegel, texto que se había vuelto muy conocido en los ambientes de filosofía universitaria a partir de 1820. Será su hermano August Wilhelm, quien había sido incluido en la disputa por el mismo Hegel, el que responda. Pero lo hará no por medio de una apología teórica, sino mediante un sarcástico poema en verso, es decir, por medio de una ironía literaria ${ }^{27}$.

\section{HISTORIA}

La última cuestión disputada considerada en esta polémica entre idealismo y romanticismo es más indirecta que las dos anteriores, pues ella debe examinar textos y testimonios de exposiciones orales que apenas se cruzaron en sus caminos, aun cuando sí se deja entrever que tuvieron noticia los unos de los otros. Una extraña coincidencia hizo que ambos pensadores dictaran lecciones de filosofía de la historia en los tiempos inmediatamente anteriores a sus repentinas muertes: Schlegel falleció el 15 de enero de 1829 a los 57 años de edad y su Philosophie der Geschichte fue leída en Viena en 18 sesiones durante abril y mayo de $1828^{28}$. Hegel dejó de existir a los 61 años el 14 de noviembre de 1831 y sus lecciones concernientes a la filosofía de la historia universal

\footnotetext{
${ }^{24}$ Ver Behler (1997, p.124.)

${ }^{25}$ Ver Friedrich Schlegel (1958 y ss., t. 17, pp. 490 y ss).

${ }^{26}$ Ver Friedrich Schlegel (1958 y ss., t. 10, pp. 16 y ss).

27 En la recensión escrita por Hegel de la edición Solgers Nachgelassene Schriften und Briefwechsel, editada en 1826 por Ludwig Tieck y Friedrich von Raumer extiende su crítica también a August Wilhelm Schlegel, cf. los así llamados Berliner Schriften en Hegel (1984, t. 11, p. 256 y ss.).

${ }^{28}$ Publicada en la actual edición crítica por J.J. Anstett en Friedrich Schlegel (1958 y ss., t. 9). Décadas antes, durante el invierno de 1805/06, había leído Schlegel frente a un pequeño círculo privado de oyentes en Colonia, ciudad que se encontraba bajo dominio napoleónico desde 1794, varias lecciones sobre la historia universal, las que permanecieron inéditas y fueron publicadas recién en la segunda mitad del siglo XX por Jean-Jacques Anstett en el tomo 14 de las obras de la edición crítica, volumen correspondiente a la segunda sección, dedicada a los escritos del Nachlaß, a partir de los apuntes tomados por uno de los asistentes, probablemente por Sulpiz Boisserée. Es decir, se trata de lo que en lenguaje técnico de las ediciones críticas se denomina Mitschrift. Cf. Friedrich Schlegel (1958 y ss., t. 14, especialmente pp. IX a XVIII de la introducción de Anstett, el acápite titulado Das Manuskript der Vorlesungen über Universalgeschichte).
} 
(Philosophie der Weltgeschichte) habían sido dictadas en la universidad de Berlín durante casi una década en los semestres de invierno entre $1822 / 23$ y 1830/3129. Sin embargo, el contexto en que se pronunciaron dichas lecciones no pudo haber sido más diferente. Mientras Hegel, profesor ordinario y luego rector de la Universidad de Berlín, lee acerca de historia en su habitual labor de docencia filosófica; en Viena, con requerida autorización imperial, Schlegel, jubilado de una corta carrera diplomática en representación de Austria, debe dirigirse en su Vorlesung a un público general compuesto -así lo exigía una expresa cláusula de dicha licencia- solo por varones burgueses y cortesanos en un salón que no respondía a un lugar específicamente académico y que él mismo debió proveer ${ }^{30}$.

Si bien se ha vuelto un tópico comparar dichos intentos desde una perspectiva que acentúa principalmente una diferencia política que explicaría satisfactoriamente su enfrentamiento teórico en torno a la comprensión de la historia ${ }^{31}$, se debe advertir, sin embargo, a mi parecer, que ambos autores desarrollan su obra bajo el alero intelectual e institucional de la Restauration, desde Viena y Berlín, es decir, desde las capitales de las naciones más importantes -Austria y Prusia- de aquellas que conforman los territorios gobernados por ese parlamento predemocrático de la dieta de Frankfurt, participando así del orden geopolítico de la Europa postnapoleónica impuesto por Metternich en el así llamado Congreso de Viena.

Es cierto que la calificación de Hegel como "filósofo de la restauración", consigna acuñada con posterioridad en la literatura revolucionaria característica del período del Vormärz, constituye una caricatura y un reduccionismo políticamente interesado, pero pretender liberarlo totalmente del rumbo político tomado por el Estado prusiano de su tiempo tampoco se condice con su actuación pública en cuanto parte del funcionariado fiscal (Beamtentum) y su estrecha relación con círculos ministeriales. Del mismo modo en que se subraya con intención apologética el contenido "virulento" contra la Restauración de la carta enviada a Niethammer el 5 de julio de $1816^{32}$, habría que reconocer su expreso

\footnotetext{
${ }^{29}$ Hegel pudo leer las lecciones de Schlegel publicadas inmediatamente el año siguiente (Viena, 1929) y las cita (Cf. Hegel 1984, t. 12, p. 79-80). Parece también muy probable que Schlegel haya tenido noticias de algunas de las lecciones que Hegel venía dictando regularmente desde mediados de la década del veinte, aunque en la lección de 1828 no lo nombra. Acerca de esta posible recepción, cf. el prólogo de J.J. Anstett al tomo 9 de la edición crítica, p. LIII. La primera edición de las lecciones hegelianas respecto de la historia fue recién en 1837.

${ }^{30}$ Ver la ya citada introducción J.J. Anstett al tomo 9 de la Kritische Ausgabe. La expresa prohibición de presencia de mujeres fue experimentada con desazón por Schlegel, pero no pudo evitar su cumplimiento.

${ }^{31}$ Este punto de vista ha sido sostenido sobre todo por J. D'Hondt en sus diversos trabajos atingentes a Hegel, para lo que sigue, cf. sobre todo su libro Hegel de 2013.

32 D’Hondt (2013, p. 20). Ver también Hoffmeister (1954, t. 2, p. 85 y ss). J. D’Hondt advierte al lector de su biografía que "la carta contra la Restauración contiene aspectos oscuros. Por otra parte, el destinatario no la quiso conservar completa, y ha llegado hasta nosotros mutilada. Puede 


\section{Gonzalo Portales}

conservadurismo respecto de la revolución de julio de 1830 que lo lleva a ubicarse del lado de la monarquía parisina y a calificar los intentos emancipadores de catastróficos, cuestión que después de su muerte tuvo que intentar aclarar su hijo, relativizando en parte su postura: "En 1830 fue interrumpida la calma política por la Revolución de Julio en Francia y sus consecuencias en Bélgica y Polonia. Mi padre veía en ella con horror una catástrofe que parecía hacer tambalear los cimientos del Estado racional, pero a diferencia de Niebuhr, no pensaba que ella conduciría al despotismo y la barbarie" "33. En el caso de Schlegel no es necesaria ninguna atenuación pues él se identifica sin más con la Restauración y su propuesta política. Más aún, podría decirse sin dificultad que su proyecto escritural desde el inicio de la revista Concordia (1820-1823) hasta las Lecciones de filosofía de la historia de 1828 consiste, precisamente, en la formulación explícita de una filosofía de la restauración o en la fundamentación filosófica de la Realpolitik de la Santa Alianza ${ }^{34}$.

$\mathrm{Si}$ se reconoce que no puede buscarse, al menos sin reservas, el motivo central de este momento de la disputa en torno al sentido filosófico de la historia en los acontecimientos sociales del orden geopolítico de la Restauración, entonces habrá que preguntarse nuevamente por aquello que enfrenta de manera polémica a Hegel y Schlegel en sus respectivas elaboraciones filosóficas respecto de la historia. Me parece plausible advertir que la rivalidad adquiere aquí claros signos confesionales, pudiendo distinguirse una abierta discordancia entre las interpretaciones del sentido propio de las dos comprensiones del cristianismo occidental o cristiandad latina en los comienzos de la modernidad, de tal manera que bien podría hablarse de una nueva confrontación entre Reforma y Catolicismo en el plano de la filosofía de la historia decimonónica. La pugna austro-prusiana se encuentra, efectivamente, marcada por la diferencia confesional y con ella por la divergencia con que estos centros de poder continental se relacionan con el legado de la historia moderna, especialmente, con aquellos elementos que Europa hereda de la Ilustración (Aufklärung).

A pesar de lo espurio del texto hegeliano de la historia universal - pues a diferencia de las lecciones acerca de la filosofía del derecho, este no proviene directamente de

\footnotetext{
aventurarse la hipótesis de que lo que se suprimió era más comprometedor que lo que se ha conservado" (p. 102). Y más adelante admite un determinado sentido del término restauración en referencia a Hegel. Dice allí: "Se le puede llamar 'filósofo de la Restauración' si lo que se quiere decir simplemente es que vivió en la época de este régimen, sufriendo sus leyes, como en Francia se llaman 'historiadores de la Restauración' a los que bajo este régimen, más o menos detestado, se dedican sobre todo a la historia de la Revolución: Augustin Thierry, Mignet, Thiers, Michelet e incluso Guizot" (p. 210).

${ }^{33}$ Günther (1970, p. 415).

${ }^{34}$ Ver Harro Zimmermann (2009, p. 321 y ss).

138 | Alpha No50 (Julio 2020) PÁGS. 125-143. ISSN 07 16-4254
} 
Hegel- ${ }^{35}$, es posible percibir, sin embargo, que en la década en que se dictan estas lecciones universitarias se produce en los últimos años un desplazamiento que minimiza el sentido epocal de la Revolución Francesa, al mismo tiempo que se acrecienta el significado de la Reforma como fundamento de la modernidad: con ello el principio rector de la historia moderna, el espíritu del mundo o Weltgeist, como se expresa Hegel, se traslada a su vez desde la historia francesa a la germana. La argumentación que justifica este cambio no se deja comprender, a mi juicio, en todos sus matices, en la medida en que en ella parece sostenerse que lo que normalmente debiese ser calificado como cierto retraso de las naciones germanas en relación con el desarrollo histórico-político de otras potencias europeas, sería precisamente lo que habría posibilitado el movimiento de la Reforma. Hegel habla alli ${ }^{36}$ de la Innigkeit des deutschen Volkes, de una interioridad del pueblo alemán que no se había dejado interrumpir por la exterioridad (̈̈ußerlichkeit) de empresas coloniales que buscaban ganar riquezas y constituir dominios mundiales (Reichtümer zu gewinnen, eine weltliche Herrschaft zusammenzubringen), alcanzando, por lo mismo, un modo puramente interior de la subjetividad que la libera religiosamente de la exterioridad material que incita a un tipo de devoción (Frömmigkeit) dispuesta a someterse a la autoridad de la institución positiva, como habría sido el caso del dominio impuesto por el Catolicismo. En este contexto, adquiere una significación especial el hecho considerado muchas veces puramente anecdótico que originó un comentario irónico de la transubstanciación hecho en clases y que produjo una denuncia y una reprimenda ministerial ${ }^{37}$, pues Hegel no se refiere despectivamente a un asunto central de la devoción católica solo movido por un afán provocador, sino que quiere insistir en ello en la constitución de una subjetividad interior que es capaz de liberarse de la mera exterioridad ( $\ddot{u} u ß e r l i c h k e i t)$ del culto que obliga a ceder frente a una doctrina medieval que ya había perdido toda fuerza conceptual para la religiosidad de su tiempo ${ }^{38}$.

Pero tal vez la identificación más importante de Hegel con la herencia de la Reforma durante los años de esta disputa confesional sea su papel protagónico en la conmemoración de la promulgación de la Confessio Augustana de 1530, en la que él, en su calidad de rector

\footnotetext{
${ }^{35}$ Acerca del estatus escritural de las lecciones hegelianas en general y de las dedicadas a la filosofía de la historia en particular, cf. Walter Jaeschke (2010, p. 367 y ss).

${ }^{36}$ Para lo que sigue, ver G.W.F. Hegel: Vorlesungen über die Philosophie der Geschichte, (Hegel t 12 p. 494 y ss.).

${ }^{37}$ VerJaeschke (2010, p. 49) y la carta de Hegel a su mujer fechada el 10 de octubre el 1827, en: Briefe Hoffmeister (1954, t. 3, p. 203 y ss.).

${ }^{38}$ Aunque es poco probable que Hegel haya tenido noticias del entusiasmo de Schlegel por este concepto central de la liturgia católica medieval, al menos su crítica coincide con un elemento que bien pudo haber sido explícito en la disputa. Ver Harro Zimmermann (2009, p. 230, el acápite titulado "Transsubstanziation - Wiedergeburt des ewigen Wortes").
} 
de la Universidad de Berlín, será el principal orador ${ }^{39}$. En esa ocasión tendrá la oportunidad de volver a la crítica de la mera exterioridad religiosa y la sumisión de la subjetividad, cuando el texto de Melanchton se refiera a las condiciones de posibilidad para la unidad de la institución eclesiástica: Et ad veram unitatem ecclesiae satis est consentire de doctrina evangelii et administratione sacramentorum. Nec necesse est ubique ese similes traditiones humanas, seu ritus aut ceremonias ab hominibus institutas ${ }^{40}$. Sin embargo, esta disputa de la positividad de la religión ya no tiene para Hegel-como lo tuvo en su juventud-una gran importancia por sí misma, sino más bien por sus consecuencias. De manera un tanto abreviada se podría decir que quizás el reparo principal radique en su tesis de que tal modo de la subjetividad culmina necesariamente en una mística y en una mistificación de la historia. A este respecto, parece interesante llamar la atención en el hecho de que Hegel no atribuye dicho misticismo solo al Schlegel tardío, sino que, como lo muestra su escrito berlinés acerca de Solger, también al joven rebelde y a todo el movimiento filosóficopoético reunido en torno a la publicación de los ejemplares de la revista Ateneo entre 1798 y 1800 y que se ha conocido en la historia de la filosofía como Escuela de Jena o Romantische Schule, aun cuando esta expresión fue acuñada por Heinrich Heine recién en $1835^{41}$.

Pero la extensión temporal de tal crítica es certera solo parcialmente. Si bien se ha transformado en un tópico identificar el 16 de abril de 1808, día en el que Friedrich Schlegel formaliza su conversión al catolicismo en la catedral de Colonia, con el momento simbólico que separa al romanticismo temprano y su impronta de rebeldía, del romanticismo tardío caracterizado por el tradicionalismo religioso y la visión reaccionaria de la política, es claro, por otra parte, que no será hasta el comienzo de la Restauración, cuando Schlegel -como ya he señalado anteriormente-asuma explícitas posiciones políticas que lo comprometerán administrativamente con el conservadurismo vienés, como enviado diplomático de Metternich en representación oficial de Austria al Frankfurter Bundestag en $1815^{42}$. Por este motivo, parece conveniente reducir el entorno de la polémica de la historia al período

\footnotetext{
${ }^{39}$ El texto latino de este discurso fue editado por Nicolai bajo el título: Oratio in Sacris Saecularibus Tertiis Traditae Confessionis Augustanae ab Universitate Regia Friderica Guilelma Berolinensi die XXV. M. Iunii A. MDCCCXXX.rite peractis habita a Georgio Guilelmo Friderico Hegel, Rectore, Philosophiae Doctore, Professore Publico Ordinario. Berolini et Stettini, A. MDCCCXXX. In Libraria Nicolai.

${ }^{40}$ Confessio Augustana, parágrafo 7: "Para que exista una verdadera unidad de la Iglesia cristiana, es suficiente que el Evangelio, íntegramente comprendido, se predique de forma unánime, y que los Sacramentos se administren de acuerdo con la Palabra divina. Y no es necesario para la verdadera unidad de la Iglesia cristiana que se celebren en todos los lugares ceremonias uniformes, de institución humana".

${ }^{41}$ Ver Hegel (1984, t. 11, p. 215). Véase también Heine (1976.), el título de este trabajo, Die Romantische Schule, hizo popular el término hasta nuestros días.

${ }^{42}$ Bleyer (1913) sigue siendo hasta nuestros días el trabajo más exhaustivo de este período.

140 | AlPHa No50 (Julio 2020) PÁGS. 125-143. ISSN 07 16-4254
} 
que va desde 1820 al 1828, esto es, desde la publicación por parte de Schlegel de los seis números de la revista Concordia hasta la Lección respecto de la filosofía de la historia dictada este último año.

Se podría decir que así como los volúmenes del Ateneo fueron los órganos de expresión de la revolución romántica en las postrimerías del siglo XVIII, así también los trabajos contenidos en los volúmenes de Concordia representarían lo más selecto del romanticismo de la Restauración. No es casualidad que prácticamente todos los intelectuales que trabajaron en dicho proyecto hayan sido fuertemente juzgados por Hegel a lo largo de toda su obra. ${ }^{43}$ Pero a partir de este momento, la crítica no caracterizó solo al modo de reacción de los adversarios ya largamente conocidos, sino que ella tuvo también como sujetos a antiguos aliados del movimiento romántico e incluso del mundo de la política ${ }^{44} \mathrm{El}$ carácter confesional e intolerante de los escritos publicados por Schlegel en Concordia, especialmente los titulados Signatur des Zeitalter provocaron el rompimiento con su hermano August Wilhelm y el cese de un largo trabajo en conjunto. El 28 de marzo de 1828, cuando Friedrich Schlegel se encuentra preparando las lecciones pertinentes a filosofía de la historia que comenzará a dictar dos meses después, recibe una carta de su hermano en la que le manifiesta: "Cuando leí Concordia fue como si me hubiese caído de las nubes; muchos de sus contenidos me provocaron la mayor indignación [...] Cómo puedes decir que tú te has mantenido distante de los diferentes partidos actuales, es algo que no puedo entender. Sobre todo porque lo que he leído en tus nuevos escritos me parece lo contrario de lo que afirmas" 45 .

Una vez constatado este giro confesional que aísla a Schlegel de parte de su entorno, habría que preguntarse, finalmente, por el significado propio de este desplazamiento religioso para la formulación de una filosofía de la historia. Me parece que una clave interpretativa de esta cuestión se manifiesta con claridad en el texto de la décima sesión de la lección de 1828. Allí se sostiene la necesidad metodológica de adoptar un punto de vista cristiano desde el que debe ser enunciada necesariamente la reflexión filosófica acerca de la historia ${ }^{46}$.

En definitiva, creo posible advertir en esta tercera comparación que no es ni la mirada sistemática, compartida por ambos, ni la construcción necesariamente teleológica, e incluso dialéctica, de sus discursos la que distancia polémicamente los caminos del pensar de Hegel y Schlegel en su interpretación filosófica de la facticidad histórica universal, sino

\footnotetext{
${ }^{43}$ Ver el detallado análisis de Otto Pöggeler (1999, pp. 70-214).

${ }^{44}$ Zimmermann (2009, p. 334) hace notar que en el círculo político en torno a Metternich la revista Concordia fue calificada despectivamente como "órgano de difusión de una oscura teosofía".

${ }^{45}$ Walzel (1890, p. 657).

${ }^{46}$ La expresión en alemán es: "von dem christlichen Gesichtspunkt für die Philosophie der Geschichte”. Ver Friedrich Schlegel (1958, t 9, p. 223 y ss).
} 
que su diferencia parece dejarse observar más claramente en lo que dice relación con el telos de dicho movimiento: mientras para Hegel la culminación de la historia tiene que ver con un proceso inmanente en la que la razón o el espíritu del mundo se realiza a sí mismo hasta su propia plenitud -y con ello hasta el fin de la historia protagonizada por esa subjetividad autoconsciente alcanzada en el cristianismo protestante a partir del siglo XVI y confirmada posteriormente por la Ilustración-; Schlegel cierra el ciclo histórico en un fin que está más allá del proceso mismo. Su teleología metahistórica queda constituida así como una finalidad escatológica en concordancia con un universalismo místico-religioso propio de cierto catolicismo europeo decimonónico y su espera del fin de los tiempos.

Este trabajo corresponde a un resultado parcial del proyecto Fondecyt $\mathrm{n}^{\circ}$ 1160378 .

\section{OBRAS CITADAS}

Behler, Ernst (1997). Ironie und literarische Moderne. Schöning Verlag.

- (1989). Unendliche Perfektivität. Europäische Romantik und Französische Revolution. Schöning Verlag.

(1988). "Friedrich Schlegels Enzyklopädie der literarischen Wissenchaften im Unterschied zu Hegels Enzyklopädie der philosophischen Wissenchaften”. En: Studien zur Romantik und zur idealistischen Philosophie. Schöning Verlag.

Bleyer, Jakob (1913). Friedrich Schlegel am Bundestage in Frankfurt. Ungedruckte Briefe Friedrich und Dorothea Schlegels nebst amtlichen Berichten und Denkschriften aus den Jahren 1815 bis 1818.Verlag von Duncker \& Humblot.

Confessio Augustana (1930). Das Augsburgische Bekenntnis von 1530. Edición Bilingüe (latín-alemán). Verlag Vandenhoeck \& Ruprecht.

D'Hondt, Jacques (2013). Hegel. Tusquets.

Dilthey, Wilhelm (1870). Das Leben Schleiermachers. Verlag Vandenhoeck \& Ruprecht.

Endres, Johannes (2017). Friedrich Schlegel Handbuch. Leben - Werk - Wirkung. J.B. Metzler Verlag.

Fichte, Johann Gottlieb (1969). Ueber den Begriff der Wissenchaftslehre (1794). Studienausgabe. Friedrich Frommann Verlag.

Hegel, G.W.F. (1984). Werke in zwanzig Bänden. Suhrkamp.

Heine, Heinrich (1976). Die Romantische Schule. Edición de Helga Weidmann. Reclam Verlag. 
Sistema, ironía e historia: Friedrich Schlegel y Hegel en disputa

Hyppolite, Jean (1946). Genèse et structure de la Phénoménologie de l'Esprit de Hegel. Aubier Éditions

Hoffmeister, Johannes (1954). Briefe von und an Hegel. 3 Vol. Felix Meiner Verlag. Jaeschke, Walter (2010). Hegel Handbuch. Leben-Werk- Schule. J.B.Metzler Verlag. Lacoue-Labarthe, Philippe y Nancy, Jean-Luc (1978). L'Absolu Littéraire. Théorie de la littérature du romanticisme allemand. Éditions du Seuil.

Lévinas, Emmanuel (1971). Totalité et Infini. Essai sur l'extériorité. Nartinus Nijhoff.

Nicolin, Günther (1970). Hegel in Berichten seiner Zeitgenossen. Felix Meiner Verlag.

Pöggeler, Otto (1999). Hegels Kritik der Romantik. Wilhelm Fink Verlag.

Portales, Gonzalo (2014). "Poética de la subjetividad y filosofía del absoluto. Sobre la recepción del pensamiento de Fichte en el primer romanticismo". En: Revista de estu (i) os sobre Fichte $n^{\circ} 9$.

Portales, Gonzalo y Onetto, Breno (2005). Poética de la infinitud. Ensayos sobre el romanticismo alemán. Ediciones Intemperie / Palinodia.

Schlegel, Friedrich (1958 y ss.). Kritische Ausgabe seiner Werke (35 tomos), hrsg. von Ernst Behler u.a. Schöning Verlag.

Walzel, Oskar (1890). Friedrich Schlegels Briefe an seinen Bruder August Wilhelm. Verlag von Speyer \& Peters.

Zimmermann, Harro (2009). Friedrich Schlegel oder die Sehnsucht nach Deutschland. Schöning Verlag. 